Vol 10, Issue 11, 2017

\title{
IDENTIFICATION OF VARIOUS DEFECTS IN PHARMACEUTICAL TABLETS USING IMAGE PROCESSING TECHNIQUES
}

\section{DURGA KARTHIK*, VIJAYAREKHA K, SARANYA S}

Department of CSE, Sastra University, Thanjavur, Tamil Nadu, India. Email: Durgakarthik@Src.Sastra.Edu

Received: 17 May 2017, Revised and Accepted: 14 July 2017

ABSTRACT

Objective: Our aim is to identify the damaged tablets from the manufacturing line using image processing techniques and remove them before packaging.

Methods: The various problems posed during inspection are broken tablets, corner chips, black or other color spots in tablets, empty blisters (without one or more tablets or capsules), foreign particles/color variation in the tablets/capsules, improper sealing, etc., Image processing techniques will be used for defect detection.

Results: Tablets are available in packed forms that are usually transparent, semi-transparent or opaque. Euclidean distance was employed for detecting defects, during testing that had a similarity of 100 for tablets with no defects, for defective blisters had similarity ranging from 98 to 41. Empty blisters had a similarity of 0 on comparing with trained images.

Conclusion: Similarity measuring based technique can accurately detect defects in the pharmaceutical tablets, hence can be adopted for removing such blisters from the manufacturing line itself.

Keywords: Tablet defects, Segmentation, Euclidean distance, Denoising, Edge detection.

(C) 2017 The Authors. Published by Innovare Academic Sciences Pvt Ltd. This is an open access article under the CC BY license (http://creativecommons. org/licenses/by/4. 0/) DOI: http://dx.doi.org/10.22159/ajpcr.2017.v10i11.20034

\section{INTRODUCTION}

Modern living has brought a comfortable way of life also has made our living far away from nature. Food, we take contains various contaminants and has lead to ailments and diseases. Hence, people have started taking allopathic medicine that gives quick remedy from ailments. The medicines are in the form of syrups, injections or in tablets. Defects such as broken tablets, foreign particles or color variation are possible during manufacturing process, that has to be detected before packaging for drug safety $[1,2]$. Manual inspection is time-consuming, and hence image processing techniques can be employed to automate the inspection process.

Canny edge detection and histogram are used for automatically determining the thresholding for a different region in image [3]. Edge detection can be effectively identifying defects in dental radiographs [4]. Gaussian filter is used for smoothen the images so as to highlight the defect in the image. Edge detection algorithms such as Roberts, Prewitt, Sobel, and Canny are used for the texture analysis process to determine the glass surface defect such as scratch and crack $[5,6]$.

Segmentation algorithm is used for the fingerprint authentication and in melanoma skin cancer detection [7-9]. A new thresholding estimation algorithm has been proposed with watershed transforming Sobel filter in frequency domain for detection of different blood cells in microscopic image [10]. Median filter with Canny edge detection is used to detect a tumor in eyes [11]. Skin diseases can be identified using image processing techniques [12].

\section{METHODS}

Tablets were obtained from Kaushik Therapeutics (p) Ltd., Chennai, and for initial study, tablet images were obtained using Canon digital camera. Tablets images for both training and testing phases were collected for analysis.
The training phase obtains the image of the tablet blisters and stores its characteristics such as shape of tablets, color of the tablets, size, number of tablets, and pixel values in the database. The testing phase consists of obtaining the tablet image from the manufacturing line and comparing it with the template image. If variation exists between the template image and the compared one, it is considered as a defect, and an alert message is raised to remove it.

\section{Algorithm for tablet defect identification}

- Step 1: Capture the image of tablet strip as template image.

- Step 2: Convert the image into gray image.

- Step 3: Filter the image to remove the noises using median filter

- Step 4: Create an edge image using Canny edge detector.

- Step 5: Store the characteristics of the image.

- Step 6: Obtain the test image.

- Step 7: Compare the input image and the template image using Euclidean distance method.

- Step 8: Alert if difference exists between the two.

The proposed architecture is given in Fig. 1.

\section{RESULTS AND DISCUSSION}

The template image was preprocessed, stored in the database and test images containing various defects were processed, compared to eliminate the tablets from the manufacturing line using Matlab. The results are displayed in Table 1 that shows the similarity measures of the test image and the template image. Euclidean distance measure was used to comparing the images. Test image with no defect yielded a similarity of 100 , one broken tablet had 98.835 and one missing tablet had 41 as similarity for an empty pack 0.34 was the similarity.

The following Figs. 2 and 3 summarizes the results of comparing the defecting image with training image. 


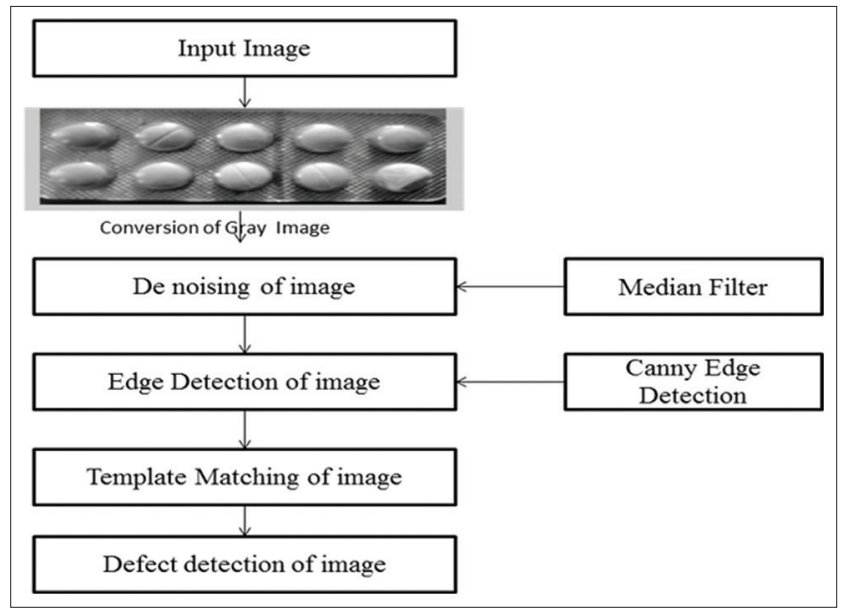

Fig. 1: Architecture of the proposed system

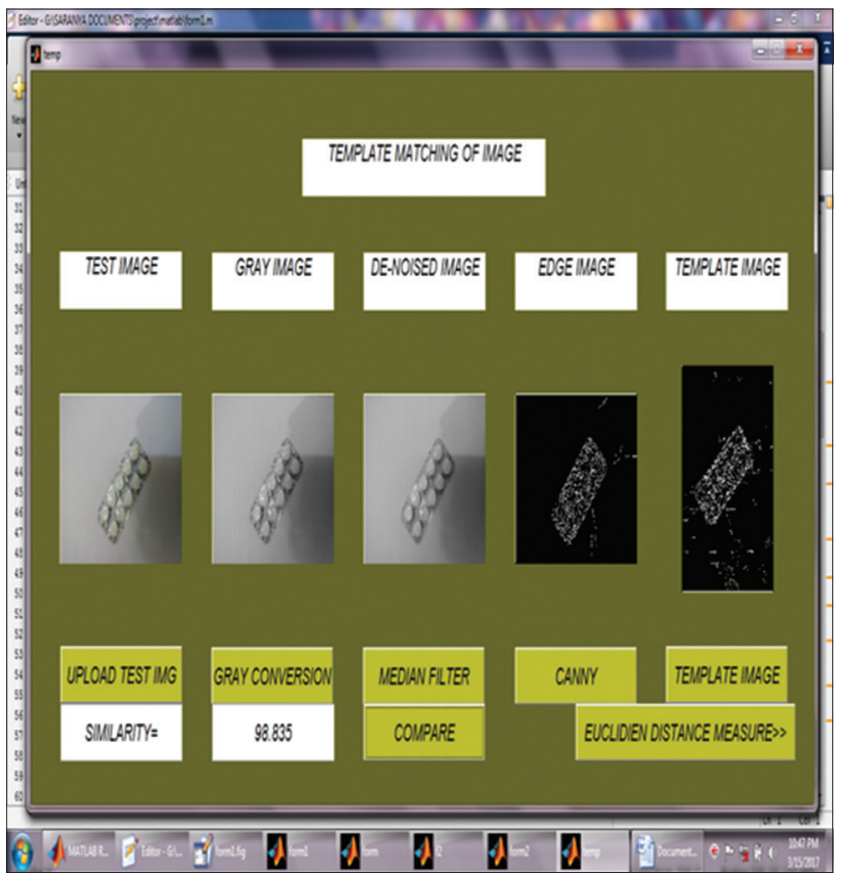

Fig. 2: One broken tablet comparison

Table 1: Comparison of training image and test images with defects

\begin{tabular}{ll}
\hline Test image & Similarity (with trained image) \\
\hline No defect & 100 \\
One broken tablet & 98.835 \\
One missing tablet & 41.4833 \\
Empty pack & 0.3452 \\
\hline
\end{tabular}

Comparison of trained and testing images is shown in Fig. 4 using a column chart showing the similarity measure.

\section{CONCLUSION}

Image processing techniques combined with Euclidean distance measure is found to be very helpful in identifying the defects in the tablets. The above method was implemented with various types of tablet blisters, and the results were convincing with an accuracy of $98 \%$. Hence, the above method can be used to identify defects in the tablets and remove them from the manufacturing line.

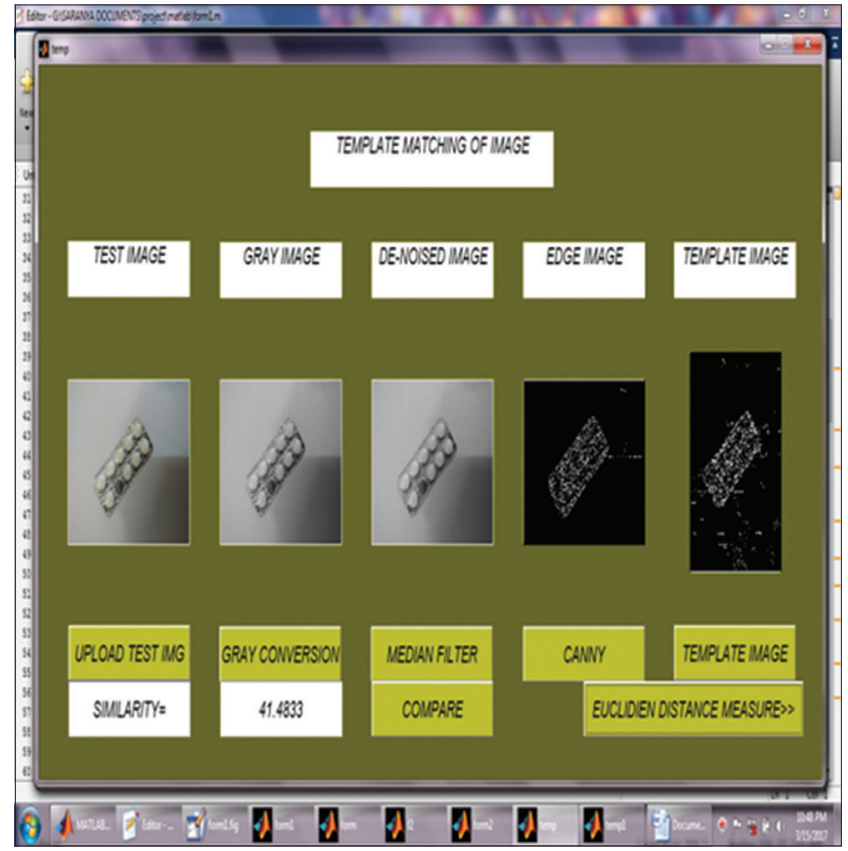

Fig. 3: One missing tablet comparison

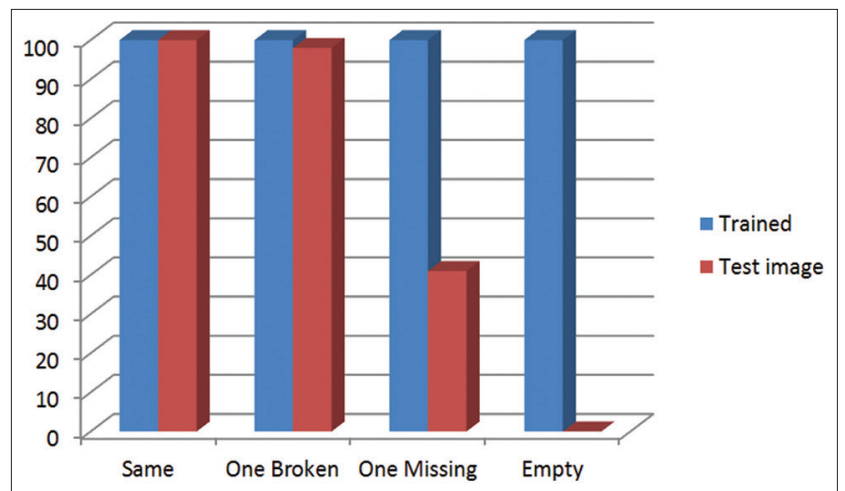

Fig. 4: Column chart is showing the similarity measure between trained and test images

\section{ACKNOWLEDGMENT}

We are thankful for the help rendered by Kaushik Therapeutics (p) Ltd., Chennai, India, for guiding us throughout the work.

\section{REFERENCES}

1. Sanket K, Garg SK. Fast dissolving tablets (FDTs): Current status, new market opportunities, recent advances in manufacturing technologies and future prospects. Int J Pharm Pharm Sci 2014;6(7):22-35.

2. Ketan S, Anuradha G, Jignasa S. Modified formulation of febuxostat: Improved efficacy and safety. Int J Pharm Pharm Sci 2015;8(1):359-366.

3. Manzoor M, Randhawa YS. Edge detection in digital image using statistical method. IOSR J Electron Commun Eng 2014;9(3):15-9.

4. Lakhani K, Minocha B, Gugnani N. Analyzing edge detection techniques for feature extraction in dental radiographs. Perspect Sci 2016;8:395-8.

5. Öztürk S, Akdemir B. Comparison of edge detection algorithms for texture analysis on glass production. Procedia Soc Behav Sci 2015; $195: 2675-82$

6. Lins RG, Givigi SN. Automatic crack detection and measurement based on image analysis. IEEE Trans Instrum Meas 2016;65(3):583-90.

7. Duarte A, Carrão L. Segmentation algorithms for thermal images. Procedia Technol 2014;16:1560-9.

8. Gnanasivam P, Muttan S. An efficient algorithm for fingerprint 
preprocessing and feature extraction Procedia Comput Sci 2010;2:133-42

9. Jain S, Jagtap V, Pise N. Computer aided melanoma skin cancer detection using image processing. Procedia Comput Sci 2015;48:735-40.

10. Biswas S, Ghoshal D. Blood cell detection using thresholding estimation based watershed transformation with sobel filter in frequency domain.
Procedia Comput Sci 2016;89:651-7.

11. Dimililer K, Ever YK, Ratemi H. Intelligent eye tumour detection system. Procedia Comput Sci 2016;102:325-32.

12. Karthik D, Vijayarekha K, Vinodha DA. Simple model for skin disease identification using image processing. Res J Pharm Biol Chem Sci 2016;7(4):2758-61. 